\title{
Neuroprotective effects of direct activation and transactivation of PDGF $\beta$ receptors
}

\author{
Maryam Vasefi ${ }^{1}$, Michael A. Beazely² \\ 'Department of Biology, Lamar University, Beaumont, TX 77710, USA. \\ ${ }^{2}$ School of Pharmacy, Faculty of Science, University of Waterloo, Kitchener, Ontario N2G 1C5, Canada.
}

Correspondence to: Prof. Michael A. Beazely, School of Pharmacy, Faculty of Science, University of Waterloo, 10 Victoria Street South, Kitchener, Ontario N2G 1C5, Canada. E-mail: mbeazely@uwaterloo.ca

How to cite this article: Vasefi M, Beazely MA. Neuroprotective effects of direct activation and transactivation of PDGF $\beta$ receptors. Vessel P/us 2020;4:24. http://dx.doi.org/10.20517/2574-1209.2020.16

Received: 11 May 2020 First Decision: 29 Jun 2020 Revised: 6 Jul 2020 Accepted: 20 Jul 2020 Published: 15 Aug 2020

Academic Editor: Shilpa Buch Copy Editor: Cai-Hong Wang Production Editor: Jing Yu

\begin{abstract}
Platelet-derived growth factor (PDGF) receptors are expressed throughout the body, including the central nervous system (CNS). Although the physiological role of PDGF receptors in the developed CNS is not fully characterized, PDGF signaling appears to provide neuroprotective effects against several neuronal insults. One of the bestcharacterized neuroprotective effects of PDGF type- $\beta$ receptors is against human immunodeficiency virus (HIV) protein-induced neurotoxicity, with potential physiological relevance to HAD. PDGF $\beta$ receptors are also neuroprotective against glutamate excitotoxicity, which is associated with both stroke and neurodegenerative diseases, including Alzheimer's disease. The neuroprotective effects of PDGF $\beta$ receptors occur both via direct activation by ligand (PDGF-BB), as well as by PDGF $\beta$ receptors activated downstream of $G$ protein-coupled receptor signaling. In addition to the involvement of PDGF signaling in various pathologies and potential therapies, there is also an emerging body of evidence that PDGF may serve as a biomarker for neurological or psychiatric diseases.
\end{abstract}

Keywords: Platelet-derived growth factor receptor, serotonin, glutamate, transactivation

\section{PDGF SIGNALING}

There are two major platelet-derived growth factor (PDGF) receptor isoforms ( $\alpha$ and $\beta$ ) and four ligand isoforms (A-D) that form homo- or hetero-dimers ${ }^{[1]}$. PDGF ligands exist as dimers of four polypeptides:




PDGF-A, - B, - C, and -D that can either homo- or hetero-dimerize into PDGF-AB, -AA, - BB, -CC, and $-D^{[2]}$. The PDGF ligands act through PDGF $\alpha$ and $\beta$ receptors ${ }^{[1]}$ and both are necessary for normal physiological development ${ }^{[2]}$. Upon binding PDGF, receptors dimerize and the tyrosine kinase domains transautophosphorylate one another on multiple tyrosine residues. Effectors such as phospholipase C (PLC) $\gamma$, phosphatidylinositol 3-kinase (PI3-kinase), Src family tyrosine kinases, tyrosine phosphatases such as SHP-2, and a GTPase-activating protein for Ras are activated after phosphorylation of the PDGF receptor ${ }^{[3]}$. Thus, by direct activation of effector proteins or via cytoplasmic adaptor proteins, PDGF receptors initiate a wide variety of downstream signaling pathways.

PDGF and its receptors are widely expressed throughout the central nervous system $(\mathrm{CNS})^{[4]}$ and are involved in neuronal growth and differentiation ${ }^{[5]}$ although their physiological role in mature neurons is not yet fully characterized. PDGF $\beta$ receptors are found in pyramidal neurons in the hippocampus ${ }^{[6,7]}$ whereas the PDGF $\alpha$ receptor and its primary ligand, PDGF-AA, are found in both neuronal ${ }^{[8]}$ and nonneuronal ${ }^{[9]}$ cells. Herein, we will briefly review the direct and indirect [i.e., GPRC - receptor tyrosine kinase (RTK) transactivation] neuroprotective effects of PDGF receptor signaling, with a focus on the PDGF $\beta$ receptors. Sil and colleagues have recently reviewed the PDGF system in the central nervous system and provided a comprehensive and detailed description of PDGF expression and signaling in CNS cell types including neurons, astrocytes, microglia, oligodendrocytes, signaling in the spinal cord, and the role of the PDGF system in the blood-brain-barrier ${ }^{[4]}$.

\section{THERAPEUTIC APPROACHES TO MODULATING PDGF SIGNALING}

Several approaches to target PDGF signaling have been proposed or evaluated, and many hold promise despite technical, logistical, and therapeutic challenges. As large growth factors, PDGF ligands are classified as biologics and would require parenteral administration. Even so, they are too large to cross the blood-brain barrier and enter the CNS, thus would require intrathecal administration directly into the cerebrospinal fluid, or direct injection into the brain, such as intracerebroventricular injection ${ }^{[10]}$. An alternative approach, discussed below, could be to indirectly transactivate PDGF receptors after the activation of G protein-coupled receptors (GPCRs). On the other hand, approaches to inhibit PDGF receptor signaling include antibodies that target PDGF ligands or receptors, small molecule inhibitors of PDGF receptor kinase activity, genetic manipulations, or targeting specific downstream signaling pathways at the receptor level ${ }^{[2]}$. Papadopolous and Lennartsson recently reviewed the approaches to inhibit PDGF signaling in cancer therapies and provided a detailed description of current and future therapies that target the PDGF system ${ }^{[1]}$. Indeed, beyond the neuroprotective roles discussed here, the PDGF system holds the potential to better understand and perhaps treat several non-neuronal disease states including cancer, fibrosis/connective tissue disorders, and vascular disease ${ }^{[12]}$.

\section{HUMAN IMMUNODEFICIENCY VIRUS - ASSOCIATED NEUROCOGNITIVE DISORDER}

Although specific dementias have distinct pathologies, disease courses, and outcomes, all include neuronal dysfunction, and many include disruptions in neurotransmitter homeostasis and signaling. Alterations in glutamate homeostasis in particular, including excitotoxicity, contributes to the pathology of ischemia and several neurodegenerative diseases ${ }^{[13]}$. As dementias progress, accumulation of toxic proteins or aggregates, coupled with neuronal dysfunction and inflammation, reduce neuronal cell viability. Thus, there is a significant interest in the role of neuroprotective signaling pathways to treat these conditions.

Human immunodeficiency virus (HIV)-associated neurocognitive disorders (HAND) are neurocognitive complications resulting from HIV infection and are classified as: asymptomatic neurocognitive impairment, mild cognitive motor disorder and HIV-associated dementia (HAD), in order of severity ${ }^{[14]}$. As the efficacy of antiretroviral therapies has improved, the transformation of HIV-infection from a fatal disease to a 
chronic one has resulted in an increase in the prevalence of HAND ${ }^{[15]}$. Despite their effectiveness in the periphery, limited penetration of antiretroviral therapies into the CNS also contributes to adverse neuronal consequences $^{[16]}$. Although the virus does not infect neurons directly, the viral proteins released from infected perivascular macrophages and microglia in the CNS can interact with neurons and cause neuronal damage and $\operatorname{loss}^{[17]}$. Several growth factors, such as brain-derived growth factor (BDNF) and fibroblast growth factor (FGF), as well as PDGF-BB, have demonstrated neuroprotective effects against HIV protein toxicity ${ }^{[18-20]}$.

Down-regulation of the PDGF-B chain at both the mRNA and protein level is observed in neuroblastoma SH-SY5Y cell cultures treated with gp120, an HIV envelope glycoprotein, and this protein exerts neurotoxic effects on SH-SY5Y cells, including increased cell death and loss of neurites ${ }^{[21,22]}$. These toxic effects are attenuated by pretreating the cells with PDGF-BB prior to incubation with gp120 in both SH-SY5Y cells and rat cortical neurons ${ }^{[21,22]}$. The neuroprotective effects appear to be associated with a reduction in apoptosis, as measured by reduced gp120-mediated activation of caspase-3 and increased $\mathrm{Bcl}-\mathrm{xL} / \mathrm{Bax}$ ratio $^{[21]}$. Peng and colleagues identified several effectors downstream of PI3K/Akt required for neuroprotective effects ${ }^{[2]}$. GSK-3 $\beta$ inactivation leads to nuclear translocation of $\beta$-catenin and NF- $\kappa B$, transcription factors that are involved in cell proliferation and differentiation ${ }^{[22]}$. Additional potential neuroprotective mechanisms include phosphorylation of Bad, downregulation of the pro-apoptotic protein, $\mathrm{Bax}$, and the inhibition of gp120-induced release of mitochondrial cytochrome $\mathrm{C}^{[22]}$.

PDGF is also neuroprotective against toxicity induced by another HIV-1 protein, Tat ${ }^{[20,23]}$. PDGF-BB activation of the PDGF $\beta$ receptor increases dendrite length and cell viability (via an anti-apoptotic effect) in rat primary midbrain neurons exposed to Tat ${ }^{[23]}$. PDGF-BB also reduces reactive oxygen species (ROS) production and caspase- 3 activation and these effects involve the regulation of ion channels, specifically, TRPC subtypes TRPC 5 and TRPC 6, and calcium influx ${ }^{[24]}$. The PDGF-mediated neuroprotection against Tat via TRPC is also confirmed in vivo: PDGF is able to protect dopaminergic neurons in adult mice injected with HIV-1 Tat and TRPC activity contributes to the protection ${ }^{[23]}$. Zhu et al. ${ }^{[25]}$ examined the PDGF-mediated neuroprotection against Tat in differentiated SH-SY5Y cells and observed the same neuroprotective effect observed by Yao in rat primary neurons and the neuroprotective effect also involves elevation of intracellular $\mathrm{Ca}^{2+}$ and requires $\mathrm{Ca}^{2+}$ influx. $\mathrm{N}$-methyl-D-aspartate (NMDA) receptors may also be involved, as the NMDA receptor antagonist MK-801 is able to abolish Tat-induced toxicity in differentiated SH-SY5Y cells ${ }^{[25]}$.

In addition to direct neuronal toxicity, HIV proteins can impair neurogenesis in the hippocampus ${ }^{[26]}$. The PDGF system is important for neurogenesis, both in the developing and mature $\mathrm{CNS}^{[27]}$. PDGF-BB can increase the number of neural progenitor cells $(\mathrm{NPC})$ in the rat hippocampus in the presence of Tat ${ }^{[26,28]}$ as well as after cocaine administration ${ }^{[26,29]}$. Similar to the previous findings by the Buch group, a role for p38, JNK, MAPK, and GSK3 $\beta$ and for the TRPC channel and calcium signaling are involved in this neuroprotective pathway ${ }^{[2]}$. Knocking-down PDGF $\beta$ receptor expression reduces neurogenesis after middle cerebral artery occlusion in mice, further suggesting a crucial role for PDGF-associated neurogenesis after neuronal injury ${ }^{[30]}$.

While many of the neuroprotective effects exerted by the PDGF system appear to be due to PDGF-BB, other ligands also exert protective effects. For example, PDGF-CC is also protective against Tat via similar downstream signaling pathways (PI3K/Akt/TRPC) as PDGF-BB ${ }^{[31]}$ and PDGF-CC was recently shown to reverse synaptic changes caused by $\mathrm{Tat}^{[31]}$.

\section{STROKE AND ISCHEMIA}

One of the major areas of PDGF neuroprotection studies has been focused on the direct inhibitory effect of PDGF on NMDA receptors and the associated neuroprotection against NMDA receptor-induced toxicity. 
Valenzuela et al. ${ }^{[32]}$ electrophysiological studies were the first to reveal the inhibitory effect of PDGF on NMDA receptors. Brief activation of PDGF receptors by PDGF-BB can trigger long-lasting inhibition on NMDA receptors in rat hippocampal slices, cultured hippocampal neurons, and Xenopus oocytes ${ }^{[32,33]}$. The mechanism of this inhibition involves $\mathrm{PLC}_{\gamma}$-induced elevation of intracellular $\mathrm{Ca}^{2+}$ and protein phosphatase activity downstream of $\mathrm{Ca}^{2+}$ signaling to modulate the NMDA receptor function ${ }^{[33]}$. Follow-up studies determined that PDGF $\beta$ receptor signaling selectively inhibits NR2B-containing NMDA receptors and decreases surface localization of NR2B subunits ${ }^{[7]}$. Abelson tyrosine kinase activated downstream of PDGF $\beta$ receptors or added directly (intracellularly) to hippocampal neurons similarly inhibits NMDA receptor signaling ${ }^{[34]}$. In addition to the inhibition of NMDA receptor signaling, PDGF-BB also reduces oxidative stress and calpain activation induced by hydrogen peroxide via reduction in intracellular calcium and via the PI3 kinase signaling pathway ${ }^{[35,36]}$.

Excess glutamatergic signaling, and subsequent over-activation of NMDA receptors, is one of the signaling events associated with neurotoxicity after stroke. Tseng and colleagues directly examined the neuroprotective effect of PDGF-BB against glutamate- or NMDA-induced excitotoxicity in cultured hippocampal neurons and found that PDGF-BB pretreatment can protect neurons from these insults in both dose- and timedependent manners ${ }^{[37]}$. Pretreatment with $10 \mathrm{ng} / \mathrm{ml}$ of PDGF-BB for $24 \mathrm{~h}$ is required for maximal effect ${ }^{[37]}$, although as little as $10 \mathrm{~min}$ of PDGF-BB pretreatment is sufficient to protect neurons from NMDA receptor-induced toxicity, if applied immediately prior to the insult $\mathrm{t}^{[7]}$. Besides the direct inhibition of the NMDA receptor, PDGF-associated neuroprotective effects against excitotoxicity are also attributed to its ability to increase glutamate reuptake by modulating the activity of the glutamate transporter, EAAC1. Sims and colleagues found that PDGF can increase the activity and surface expression of EAAC1 and these effects depend on the activation of PI3 kinase ${ }^{[38]}$ and the activation of $\mathrm{Akt}^{[39]}$.

In vivo, pretreatment with PDGF-BB, but not AA, two days before forebrain ischemia in rats protects CA1 pyramidal neurons from delayed neuronal death on day 7 after ischemia in a dose-dependent manner ${ }^{[40]}$. Continuous infusion of PDGF-BB for 7 days into the cerebral ventricles of gerbils with transient forebrain ischemia improves their performance on a passive avoidance task and subsequent histological examinations revealed that PDGF-BB increases neuronal survival and the number of remaining synapses ${ }^{[4]]}$. Administration of PDGF-BB into the left neocortex of Sprague-Dawley rats for 7 or 14 days before ischemia decreases the neocortical infarction with the size of infarction the smallest in the 14-day group ${ }^{[42]}$. EgawaTsuzuki and colleagues found that PDGF-B infusion before and after NMDA injection reduces the size of lesions in young rats when their endogenous expression of PDGF-B in neurons is low ${ }^{[43]}$.

Clearly, the application of PDGF ligands preceding a controlled insult is neuroprotective, but likely not a feasible therapeutic approach in humans where the insult is not typically predictable. Interestingly, PDGF signaling may be used as an endogenous neuroprotective response by the CNS after the damage has already occurred. For example, focal ischemia in rat brains causes a rapid increase in PDGF-B chain isoform mRNA transcripts that peaks at $24 \mathrm{~h}^{[44]}$ (a similar upregulation of PDGF-B occurs in myocardial tissue after ischemia ${ }^{[45]}$ ). PDGF-BB expression is also increased after ischemic preconditioning in the gerbil hippocampus ${ }^{[46]}$. PDGF $\beta$ receptor expression rises rapidly after ischemia in the rat brain ${ }^{[47]}$. Furthermore, the expression of PDGF-A and PDGF-B mRNA and PDGF-BB and PDGF-AB dimer protein expression rises in neurons and supports cells surrounding areas damaged by ischemic events in humans ${ }^{[48]}$. In addition, mice without the PDGF $\beta$ receptor gene are vulnerable to NMDA receptor-induced excitotoxicity in terms of increased cell death and lesion size ${ }^{[49]}$. There is a considerable amount of evidence that activation of the PDGF system prior to these neuronal insults is neuroprotective and that these insults also upregulate PDGF system components. 


\section{A NOTE ON THE BLOOD-BRAIN BARRIER}

Although not a direct neuronal or neuroprotective effect, PDGF signaling has a significant, perhaps much more significant, indirect impact on neuronal health due to its effects on pericytes, angiogenesis, and the blood-brain barrier. As our focus is on the neuroprotective effects of PDGF signaling, we will not review PDGF's vascular effects in detail as these have been reviewed elsewhere ${ }^{[24,50,51]}$. While the role of PDGF signaling in the blood-brain barrier is not yet fully understood, several lines of evidence demonstrate that PDGF signaling increases blood-brain barrier permeability, resulting in neuronal damage, while others have demonstrated positive effects of PDGF signaling on blood-brain barrier function and recovery after neuronal insults. Examples of the impact, both positive and negative, of PDGF signaling have been reported for stroke $e^{[52-54]}$, HAND $^{[24,55,56]}$, Alzheimer's disease $(\mathrm{AD})^{[57]}$, Parkinson's disease $(\mathrm{PD})^{[58]}$, epilepsy ${ }^{[59]}$, and neuroinflammation ${ }^{[60,61]}$.

\section{ALZHEIMER'S DISEASE}

$\mathrm{AD}$ is a progressive neurodegenerative disease characterized by cognitive decline ${ }^{[62]}$. One of the hallmarks of $\mathrm{AD}$ is amyloid- $\beta$ accumulation which begins decades before clinical diagnosis of the disease ${ }^{[62]}$. There is emerging evidence that the PDGF system is involved in AD pathology. For example, PDGF-BB is one of the cytokines that differs between post-mortem patients with high amyloid- $\beta$ accumulation loads that did not have cognitive symptoms $v$ s. those that did experience cognitive decline ${ }^{[63]}$. Amyloid- $\beta$ is produced by the proteolytic cleavage of the amyloid precursor protein (APP) ${ }^{[64]}$ and the PDGF system appears to play a role in APP homeostasis. In astrocytes, PDGF treatment increases sAPP $\alpha$ activity two-fold and this effect is blocked by the broad-spectrum tyrosine kinase inhibitor, genistein ${ }^{[65]}$. Using a recombinant protein expressing system in Hela cells, Gianni and Zambrano, along with other colleagues, demonstrated that PDGF-BB can induce $\gamma$-secretase mediated APP proteolysis by activating PDGF receptors and found Src and Rac1 but not ERKs, PI3K or Abl tyrosine kinase were involved in that signaling pathway ${ }^{[6,67]}$. Further studies have identified that the cytodomain of APP (containing YENPTY motif) is required for PDGFinduced APP proteolysis ${ }^{[6,67]}$.

The mechanism(s) of amyloid- $\beta$ toxicity in neurons involve both non-specific and receptor-dependent pathways ${ }^{[68-70]}$, including interactions with receptor tyrosine kinases ${ }^{[69]}$. In SH-SY5Y cells, application of PDGF-BB increases cell number and this effect is inhibited in the presence of amyloid- $\beta^{[71]}$. PDGF-BBinduced phosphorylation of the PDGF $\beta$ receptor is also blocked by amyloid- $\beta$, however, no physical association between amyloid- $\beta$-PDGF-BB was detected ${ }^{[71]}$. Indirect activation (i.e., transactivation - see the section below) was not affected by amyloid $-\beta^{[71]}$. We have previously demonstrated that direct or indirect (GPCR-mediated) activation of the PDGF $\beta$ receptor can protect neurons against NMDA receptordependent toxicity ${ }^{[72]}$. However in the presence of amyloid- $\beta$, PDGF-BB application was no longer able to prevent NMDA-induced toxicity, suggesting that amyloid- $\beta$ may promote neurodegeneration by blocking a key neuroprotective pathway in the brain.

\section{PARKINSON'S DISEASE}

Similar to AD, there is evidence that PDGF and other neurotrophic factors may also be involved in the pathogenesis and treatment of $\mathrm{PD}$ due to both its neuroprotective and trophic effects (see two recent reviews ${ }^{[73,74]}$ ). The levels of PDGF-BB and PDGF-AA are correlated with the level of plasma $\alpha$-synuclein in PD patients, suggesting PDGF may be a potential biomarker for $\mathrm{PD}^{[75]}$. PDGF-BB provides protective effects against a toxicant associated with PD, rotenone, by countering its effects on mitochondria and ROS production in both cell lines and in astrocytes ${ }^{[76,77]}$. With the latter finding among those sparking interest in targeting PDGF signaling in astrocytes in neurologic disease as a therapeutic approach ${ }^{[78,79]}$. These and other studies led to human trials with PDGF-BB in phase I clinical trial for PD (a dose-escalation study of intracerebroventricular PDGF-BB delivered via an infusion pump, from 0.2 to $5 \mu \mathrm{g} /$ day) ${ }^{[10]}$. PDGF-BB 
showed good tolerability and resulted in a dose-dependent increase in dopamine transporter expression measure via positron emission tomography (PET) scan, but little to no symptomatic improvement ${ }^{[10]}$. Analogous to our own findings demonstrating amyloid- $\beta$ could impair PDGF receptor signaling ${ }^{[71]}$, one of the pathogenic processes in PD, a-synuclein, impairs some PDGF-induced processes (chemotaxis) but not others (intracellular signaling to ERK) ${ }^{[80]}$. In addition to PDGF-BB, PDGF-CC has demonstrated neuroprotective effects in several neuronal toxicity studies, including 6-OH-dopamine-induced neuronal cell death, in signaling pathways associated with GSK $3 \beta^{[81]}$.

\section{NEUROPROTECTIVE EFFECTS OF PDGF RECEPTOR TRANSACTIVATION}

Growth factor receptors such as the PDGF $\beta$ receptor can be activated directly by their endogenous ligand or be transactivated by signals initiated through other receptors in the absence of PDGF ligand ${ }^{[82,83]}$. Classic transactivation of growth factor receptors occurs within minutes after activation of GPCRs. For example, the activation of D2-family dopamine receptors initiates an intracellular signaling cascade that increases PDGF $\beta$ receptor phosphorylation and activity, including an increase in ERK $1 / 2$ phosphorylation ${ }^{[84]}$. The transactivation of RTK receptors by GPCR initiation may regulate a signaling cascade that differs from those activated by direct ligand binding ${ }^{[85]}$.

5-HT7 receptors are Gos-coupled receptors; their activation leads to an increase both in adenylyl cyclase activity and in the intracellular level of cyclic $\mathrm{AMP}^{[86]} .5-\mathrm{HT} 7$ receptors are expressed in the prefrontal cortex, hippocampus, thalamus, hypothalamus, and the amygdala in both neurons and support cells ${ }^{[87]}$. 5 - HT7 receptors increase the number of dendrites and promote synapse formation in neurons ${ }^{[88]} .5-\mathrm{HT}$ receptors including the 5-HT7 receptor are also able to transactivate PDGF $\beta$ receptors (and TrkB receptors) ${ }^{[89,90]}$.

PDGF $\beta$ receptors can inhibit NR2B-containing NMDA receptors and this can result in neuroprotective effects. Similarly, transactivating PDGF $\beta$ receptors, downstream of dopamine receptors, also results in neuroprotection against NMDA-induced toxicity ${ }^{[91]} .5-\mathrm{HT} 7$ receptor agonists also lead to an increase in the expression of PDGF $\beta$ receptors and its phosphorylation at tyrosine 1021, the PLC $\gamma$ binding site associated with PDGF-induced inhibition of NMDA-evoked currents ${ }^{[89]}$. After the application of 5-HT7 receptor agonists to cultured cells or primary hippocampal or cortical cultures, the cells are resistant to NMDAinduced toxicity due to the upregulation and activation of PDGF $\beta$ receptors ${ }^{[72]}$. In addition, activation of the 5-HT7 receptor also selectively changes the expression and phosphorylation state of the NR2B subunit of the NMDA receptor, similar to what was observed with dopamine and PDGF-BB-induced changes in NMDA receptor expression ${ }^{[72]}$. Interestingly, although long-term agonist treatment with 5-HT7 ligands inhibits NMDA receptor activity via PDGF $\beta$ receptors, acute, direct activation of 5-HT7 receptors increases NMDA-evoked currents ${ }^{[92]}$.

PDGF $\beta$ receptor transactivation may also play a role in BBB function. PDGF $\beta$ receptor signaling protects endothelial cell function and BBB integrity after $\beta$-arrestin activation subsequent to protease-activated receptor $1^{[93]}$. Thus, in addition to GPCR-PDGF $\beta$ receptor transactivating and directly impacting neuronal health, transactivation or indirect activation of PDGF signaling may also impact BBB integrity in the context of stroke or other neurological diseases.

\section{PDGF AS A BIOMARKER}

As noted above, the impact of the PDGF system on the vasculature may be more important clinically than the direct effects of this signaling pathway on neurons. Similarly, although there are intriguing possibilities for the development of novel treatments targeting the PDGF system in neuronal health, using PDGF ligands as biomarkers for disease may be more impactful, at least in the short term. For example, the presence of PDGF-AA in cerebrospinal fluid (CSF) of HIV-infected individuals was negatively associated 
with HAND ${ }^{[94]}$. Stroke patients have higher levels of circulating PDGF $\beta$ receptor-positive cells ${ }^{[95]}$. PDGF-BB is consistently among the growing number of proteins and molecules identified as biomarkers in the CSF of $\mathrm{AD}$ patients ${ }^{[96-98]}$ and is potentially a serum biomarker for $\mathrm{PD}^{[99]}$. PDGF-BB levels are also elevated in patients with amyotrophic lateral sclerosis ${ }^{[100]}$. PDGF-BB may be a biomarker for schizophrenia ${ }^{[101]}$ as well as having links to the disease via genetic differences in both PDGF-B and PDGF $\beta$ receptor genes ${ }^{[102]}$. Last, mutations in PDGF-B and PDGF $\beta$ receptor genes are both biomarkers for, and causative agents of, familial brain calcification $^{[103,104]}$.

\section{CONCLUSION}

PDGF signaling is crucial for healthy CNS development. In recent years, its role in the developed CNS, and even in the aging CNS, has been linked to various neuropathologies and neuroprotective pathways. Understanding, and possibly targeting, the PDGF system will be crucial to our understanding and treatment of stroke and neuronal damage, dementias including HAND and Alzheimer's disease, and in Parkinson's disease. In addition to understanding ligand-activated PDGF receptor signaling, indirect, GPCR-mediated transactivation of the PDGF $\beta$ receptor, provides a link between GPCR-targeted therapies and PDGF system changes.

\section{DECLARATIONS}

\section{Authors' contributions}

Made substantial contributions to conception and design of the study: Vasefi M, Beazely MA

Participated in drafting the article and revising the content: Vasefi $M$

Contributed in revising the article and approved the revised version: Beazely MA

\section{Availability of data and materials}

Not applicable

\section{Financial support and sponsorship}

None.

\section{Conflicts of interest}

Both authors declared that there are no conflicts of interest.

\section{Ethical approval and consent to participate}

Not applicable.

\section{Consent for publication}

Not applicable.

\section{Copyright}

(c) The Author(s) 2020.

\section{REFERENCES}

1. Heldin CH, Ostman A, Ronnstrand L. Signal transduction via platelet-derived growth factor receptors. Biochim Biophys Acta 1998;1378:F79-113.

2. Kazlauskas A. PDGFs and their receptors. Gene 2017;614:1-7.

3. Heldin CH, Westermark B. Mechanism of action and in vivo role of platelet-derived growth factor. Physiol Rev 1999;79:1283-316.

4. Sil S, Periyasamy P, Thangaraj A, Chivero ET, Buch S. PDGF/PDGFR axis in the neural systems. Mol Aspects Med 2018;62:63-74.

5. Williams BP, Park JK, Alberta JA, Muhlebach SG, Hwang GY, et al. A PDGF-regulated immediate early gene response initiates neuronal differentiation in ventricular zone progenitor cells. Neuron 1997;18:553-62.

6. Smits A, Kato M, Westermark B, Nister M, Heldin CH, et al. Neurotrophic activity of platelet-derived growth factor (PDGF): rat neuronal 
cells possess functional PDGF beta-type receptors and respond to PDGF. Proc Natl Acad Sci U S A 1991;88:8159-63.

7. Beazely MA, Lim A, Li H, Trepanier C, Chen X, et al. Platelet-derived growth factor selectively inhibits NR2B-containing N-methyl-Daspartate receptors in CA1 hippocampal neurons. J Biol Chem 2009;284:8054-63.

8. Yeh HJ, Ruit KG, Wang YX, Parks WC, Snider WD, et al. PDGF A-chain gene is expressed by mammalian neurons during development and in maturity. Cell 1991;64:209-16.

9. Yeh HJ, Silos-Santiago I, Wang YX, George RJ, Snider WD, et al. Developmental expression of the platelet-derived growth factor alphareceptor gene in mammalian central nervous system. Proc Natl Acad Sci U S A 1993;90:1952-6.

10. Paul G, Zachrisson O, Varrone A, Almqvist P, Jerling M, et al. Safety and tolerability of intracerebroventricular PDGF-BB in Parkinson's disease patients. J Clin Invest 2015;125:1339-46.

11. Papadopoulos N, Lennartsson J. The PDGF/PDGFR pathway as a drug target. Mol Aspects Med 2018;62:75-88.

12. Ishii Y, Hamashima T, Yamamoto S, Sasahara M. Pathogenetic significance and possibility as a therapeutic target of platelet derived growth factor. Pathol Int 2017;67:235-46.

13. Doble A. The role of excitotoxicity in neurodegenerative disease: implications for therapy. Pharmacol Ther 1999;81:163-221.

14. Ghafouri M, Amini S, Khalili K, Sawaya BE. HIV-1 associated dementia: symptoms and causes. Retrovirology 2006;3:28.

15. Schouten J, Cinque P, Gisslen M, Reiss P, Portegies P. HIV-1 infection and cognitive impairment in the cART era: a review. AIDS 2011;25:561-75.

16. Thomas SA. Anti-HIV drug distribution to the central nervous system. Curr Pharm Des 2004;10:1313-24

17. Lindl KA, Marks DR, Kolson DL, Jordan-Sciutto KL. HIV-associated neurocognitive disorder: pathogenesis and therapeutic opportunities. J Neuroimmune Pharmacol 2010;5:294-309.

18. Bachis A, Mocchetti I. Brain-derived neurotrophic factor is neuroprotective against human immunodeficiency virus- 1 envelope proteins. Ann N Y Acad Sci 2005;1053:247-57.

19. Sanders VJ, Everall IP, Johnson RW, Masliah E. Fibroblast growth factor modulates HIV coreceptor CXCR4 expression by neural cells. HNRC Group. J Neurosci Res 2000;59:671-9.

20. Malik S, Khalique H, Buch S, Seth P. A growth factor attenuates HIV-1 Tat and morphine induced damage to human neurons: implication in HIV/AIDS-drug abuse cases. PLoS One 2011;6:e18116.

21. Peng F, Dhillon N, Callen S, Yao H, Bokhari S, et al. Platelet-derived growth factor protects neurons against gp120-mediated toxicity. J Neurovirol 2008; 14:62-72.

22. Peng F, Dhillon NK, Yao H, Zhu X, Williams R, et al. Mechanisms of platelet-derived growth factor-mediated neuroprotection-implications in HIV dementia. Eur J Neurosci 2008;28:1255-64.

23. Yao H, Peng F, Dhillon N, Callen S, Bokhari S, et al. Involvement of TRPC channels in CCL2-mediated neuroprotection against tat toxicity. J Neurosci 2009;29:1657-69.

24. Yao H, Bethel-Brown C, Niu F, Yang L, Peng F, et al. Yin and Yang of PDGF-mediated signaling pathway in the context of HIV infection and drug abuse. J Neuroimmune Pharmacol 2014;9:161-7.

25. Zhu X, Yao H, Peng F, Callen S, Buch S. PDGF-mediated protection of SH-SY5Y cells against Tat toxin involves regulation of extracellular glutamate and intracellular calcium. Toxicol Appl Pharmacol 2009;240:286-91.

26. Yao H, Duan M, Yang L, Buch S. Platelet-derived growth factor-BB restores human immunodeficiency virus Tat-cocaine-mediated impairment of neurogenesis: role of TRPC1 channels. J Neurosci 2012;32:9835-47.

27. Funa K, Sasahara M. The roles of PDGF in development and during neurogenesis in the normal and diseased nervous system. J Neuroimmune Pharmacol 2014;9:168-81.

28. Chao J, Yang L, Yao H, Buch S. Platelet-derived growth factor-BB restores HIV Tat -mediated impairment of neurogenesis: role of GSK3beta/beta-catenin. J Neuroimmune Pharmacol 2014;9:259-68.

29. Yang L, Chen X, Hu G, Cai Y, Liao K, et al. Mechanisms of platelet-derived growth factor-BB in restoring HIV tat-cocaine-mediated impairment of neuronal differentiation. Mol Neurobiol 2016;53:6377-87.

30. Sato H, Ishii Y, Yamamoto S, Azuma E, Takahashi Y, et al. PDGFR-beta plays a key role in the ectopic migration of neuroblasts in cerebral stroke. Stem Cells 2016;34:685-98.

31. Hu G, Niu F, Liao K, Periyasamy P, Sil S, et al. HIV-1 Tat-induced astrocytic extracellular vesicle miR-7 impairs synaptic architecture. J Neuroimmune Pharmacol 2019.

32. Valenzuela CF, Xiong Z, MacDonald JF, Weiner JL, Frazier CJ, et al. Platelet-derived growth factor induces a long-term inhibition of N-methyl-D-aspartate receptor function. J Biol Chem 1996;271:16151-9.

33. Lei S, Lu WY, Xiong ZG, Orser BA, Valenzuela CF, et al. Platelet-derived growth factor receptor-induced feed-forward inhibition of excitatory transmission between hippocampal pyramidal neurons. J Biol Chem 1999;274:30617-23.

34. Beazely MA, Weerapura M, MacDonald JF. Abelson tyrosine kinase links PDGFbeta receptor activation to cytoskeletal regulation of NMDA receptors in CA1 hippocampal neurons. Mol Brain 2008;1:20.

35. Zheng LS, Ishii Y, Zhao QL, Kondo T, Sasahara M. PDGF suppresses oxidative stress induced Ca2+ overload and calpain activation in neurons. Oxid Med Cell Longev 2013;2013:367206.

36. Zheng L, Ishii Y, Tokunaga A, Hamashima T, Shen J, et al. Neuroprotective effects of PDGF against oxidative stress and the signaling pathway involved. J Neurosci Res 2010;88:1273-84.

37. Tseng HC, Dichter MA. Platelet-derived growth factor-BB pretreatment attenuates excitotoxic death in cultured hippocampal neurons. Neurobiol Dis 2005;19:77-83.

38. Sims KD, Straff DJ, Robinson MB. Platelet-derived growth factor rapidly increases activity and cell surface expression of the EAAC1 
subtype of glutamate transporter through activation of phosphatidylinositol 3-kinase. J Biol Chem 2000;275:5228-37.

39. Krizman-Genda E, Gonzalez MI, Zelenaia O, Robinson MB. Evidence that Akt mediates platelet-derived growth factor-dependent increases in activity and surface expression of the neuronal glutamate transporter, EAAC1. Neuropharmacology 2005;49:872-82.

40. Iihara K, Hashimoto N, Tsukahara T, Sakata M, Yanamoto H, et al. Platelet-derived growth factor-BB, but not -AA, prevents delayed neuronal death after forebrain ischemia in rats. J Cereb Blood Flow Metab 1997;17:1097-106.

41. Kawabe T, Wen TC, Matsuda S, Ishihara K, Otsuda H, et al. Platelet-derived growth factor prevents ischemia-induced neuronal injuries in vivo. Neurosci Res 1997;29:335-43.

42. Sakata M, Yanamoto H, Hashimoto N, Iihara K, Tsukahara T, et al. Induction of infarct tolerance by platelet-derived growth factor against reversible focal ischemia. Brain Res 1998;784:250-5.

43. Egawa-Tsuzuki T, Ohno M, Tanaka N, Takeuchi Y, Uramoto H, et al. The PDGF B-chain is involved in the ontogenic susceptibility of the developing rat brain to NMDA toxicity. Exp Neurol 2004;186:89-98.

44. Iihara K, Sasahara M, Hashimoto N, Uemura Y, Kikuchi H, et al. Ischemia induces the expression of the platelet-derived growth factor-B chain in neurons and brain macrophages in vivo. J Cereb Blood Flow Metab 1994;14:818-24.

45. Suzuki J, Baba S, Ohno I, Endoh M, Nawata J, et al. Immunohistochemical analysis of platelet-derived growth factor-B expression in myocardial tissues in hypertrophic cardiomyopathy. Cardiovasc Pathol 1999;8:223-31.

46. Lee JC, Kim YH, Lee TK, Kim IH, Cho JH, et al. Effects of ischemic preconditioning on PDGF-BB expression in the gerbil hippocampal CA1 region following transient cerebral ischemia. Mol Med Rep 2017;16:1627-34.

47. Ohno M, Sasahara M, Narumiya S, Tanaka N, Yamano T, et al. Expression of platelet-derived growth factor B-chain and beta-receptor in hypoxic/ischemic encephalopathy of neonatal rats. Neuroscience 1999;90:643-51.

48. Krupinski J, Issa R, Bujny T, Slevin M, Kumar P, et al. A putative role for platelet-derived growth factor in angiogenesis and neuroprotection after ischemic stroke in humans. Stroke 1997;28:564-73.

49. Ishii Y, Oya T, Zheng L, Gao Z, Kawaguchi M, et al. Mouse brains deficient in neuronal PDGF receptor-beta develop normally but are vulnerable to injury. J Neurochem 2006;98:588-600.

50. Nikolakopoulou AM, Zhao Z, Montagne A, Zlokovic BV. Regional early and progressive loss of brain pericytes but not vascular smooth muscle cells in adult mice with disrupted platelet-derived growth factor receptor-beta signaling. PLoS One 2017;12:e0176225.

51. Lewandowski SA, Fredriksson L, Lawrence DA, Eriksson U. Pharmacological targeting of the PDGF-CC signaling pathway for bloodbrain barrier restoration in neurological disorders. Pharmacol Ther 2016;167:108-19.

52. Shen J, Ishii Y, Xu G, Dang TC, Hamashima T, et al. PDGFR-beta as a positive regulator of tissue repair in a mouse model of focal cerebral ischemia. J Cereb Blood Flow Metab 2012;32:353-67.

53. Shibahara T, Ago T, Nakamura K, Tachibana M, Yoshikawa Y, et al. Pericyte-mediated tissue repair through PDGFRbeta promotes periinfarct astrogliosis, oligodendrogenesis, and functional recovery after acute ischemic stroke. eNeuro 2020;7.

54. Shen J, Xu G, Zhu R, Yuan J, Ishii Y, et al. PDGFR-beta restores blood-brain barrier functions in a mouse model of focal cerebral ischemia. J Cereb Blood Flow Metab 2019;39:1501-15.

55. Niu F, Yao H, Liao K, Buch S. HIV Tat 101-mediated loss of pericytes at the blood-brain barrier involves PDGF-BB. Ther Targets Neurol Dis 2015;2:e471.

56. Niu F, Yao H, Zhang W, Sutliff RL, Buch S. Tat 101-mediated enhancement of brain pericyte migration involves platelet-derived growth factor subunit B homodimer: implications for human immunodeficiency virus-associated neurocognitive disorders. J Neurosci 2014;34:11812-25.

57. Miners JS, Schulz I, Love S. Differing associations between Abeta accumulation, hypoperfusion, blood-brain barrier dysfunction and loss of PDGFRB pericyte marker in the precuneus and parietal white matter in Alzheimer's disease. J Cereb Blood Flow Metab 2018;38:103-15.

58. Padel T, Ozen I, Boix J, Barbariga M, Gaceb A, et al. Platelet-derived growth factor-BB has neurorestorative effects and modulates the pericyte response in a partial 6-hydroxydopamine lesion mouse model of Parkinson's disease. Neurobiol Dis 2016;94:95-105.

59. Milesi S, Boussadia B, Plaud C, Catteau M, Rousset MC, et al. Redistribution of PDGFRbeta cells and NG2DsRed pericytes at the cerebrovasculature after status epilepticus. Neurobiol Dis 2014;71:151-8.

60. Bethel-Brown C, Yao H, Hu G, Buch S. Platelet-derived growth factor (PDGF)-BB-mediated induction of monocyte chemoattractant protein 1 in human astrocytes: implications for HIV-associated neuroinflammation. J Neuroinflammation 2012;9:262.

61. Jansson D, Scotter EL, Rustenhoven J, Coppieters N, Smyth LC, et al. Interferon-gamma blocks signalling through PDGFRbeta in human brain pericytes. J Neuroinflammation 2016;13:249.

62. Hardy JA, Higgins GA. Alzheimer's disease: the amyloid cascade hypothesis. Science 1992;256:184-5.

63. Barroeta-Espar I, Weinstock LD, Perez-Nievas BG, Meltzer AC, Siao Tick Chong M, et al. Distinct cytokine profiles in human brains resilient to Alzheimer's pathology. Neurobiol Dis 2019;121:327-37.

64. O'Brien RJ, Wong PC. Amyloid precursor protein processing and Alzheimer's disease. Annu Rev Neurosci 2011;34:185-204.

65. Kim C, Jang CH, Bang JH, Jung MW, Joo I, et al. Amyloid precursor protein processing is separately regulated by protein kinase $\mathrm{C}$ and tyrosine kinase in human astrocytes. Neurosci Lett 2002;324:185-8.

66. Gianni D, Zambrano N, Bimonte M, Minopoli G, Mercken L, et al. Platelet-derived growth factor induces the beta-gamma-secretasemediated cleavage of Alzheimer's amyloid precursor protein through a Src-Rac-dependent pathway. J Biol Chem 2003;278:9290-7.

67. Zambrano N, Gianni D, Bruni P, Passaro F, Telese F, et al. Fe65 is not involved in the platelet-derived growth factor-induced processing of Alzheimer's amyloid precursor protein, which activates its caspase-directed cleavage. J Biol Chem 2004;279:16161-9.

68. Friedman R, Pellarin R, Caflisch A. Amyloid aggregation on lipid bilayers and its impact on membrane permeability. J Mol Biol 
2009;387:407-15

69. Xie L, Helmerhorst E, Taddei K, Plewright B, Van Bronswijk W, et al. Alzheimer's beta-amyloid peptides compete for insulin binding to the insulin receptor. J Neurosci 2002;22:RC221.

70. Minano-Molina AJ, Espana J, Martin E, Barneda-Zahonero B, Fado R, et al. Soluble oligomers of amyloid-beta peptide disrupt membrane trafficking of alpha-amino-3-hydroxy-5-methylisoxazole-4-propionic acid receptor contributing to early synapse dysfunction. J Biol Chem 2011;286:27311-21.

71. Liu H, Saffi GT, Vasefi MS, Choi Y, Kruk JS, et al. Amyloid-beta inhibits PDGFbeta receptor activation and prevents PDGF-BBInduced neuroprotection. Curr Alzheimer Res 2018;15:618-27.

72. Vasefi MS, Kruk JS, Heikkila JJ, Beazely MA. 5-Hydroxytryptamine type 7 receptor neuroprotection against NMDA-induced excitotoxicity is PDGFbeta receptor dependent. J Neurochem 2013;125:26-36.

73. Paul G, Sullivan AM. Trophic factors for Parkinson's disease: where are we and where do we go from here? Eur J Neurosci 2019;49:440-52.

74. Tome D, Fonseca CP, Campos FL, Baltazar G. Role of neurotrophic factors in Parkinson's disease. Curr Pharm Des 2017;23:809-38.

75. Lue LF, Schmitz CT, Snyder NL, Chen K, Walker DG, et al. Converging mediators from immune and trophic pathways to identify Parkinson disease dementia. Neurol Neuroimmunol Neuroinflamm 2016;3:e193.

76. Cabezas R, Avila MF, Gonzalez J, El-Bacha RS, Barreto GE. PDGF-BB protects mitochondria from rotenone in T98G cells. Neurotox Res 2015;27:355-67.

77. Cabezas R, Vega-Vela NE, Gonzalez-Sanmiguel J, Gonzalez J, Esquinas P, et al. PDGF-BB preserves mitochondrial morphology, attenuates ROS production, and upregulates neuroglobin in an astrocytic model under rotenone insult. Mol Neurobiol 2018;55:3085-95.

78. Miyazaki I, Asanuma M. Therapeutic strategy of targeting astrocytes for neuroprotection in Parkinson's disease. Curr Pharm Des 2017;23:4936-47.

79. Cabezas R, Baez-Jurado E, Hidalgo-Lanussa O, Echeverria V, Ashrad GM, et al. Growth factors and neuroglobin in astrocyte protection against neurodegeneration and oxidative stress. Mol Neurobiol 2019;56:2339-51.

80. Okada T, Hirai C, Badawy SMM, Zhang L, Kajimoto T, et al. Impairment of PDGF-induced chemotaxis by extracellular alpha-synuclein through selective inhibition of Rac1 activation. Sci Rep 2016;6:37810.

81. Tang Z, Arjunan P, Lee C, Li Y, Kumar A, et al. Survival effect of PDGF-CC rescues neurons from apoptosis in both brain and retina by regulating GSK3beta phosphorylation. J Exp Med 2010;207:867-80.

82. Shah BH, Catt KJ. GPCR-mediated transactivation of RTKs in the CNS: mechanisms and consequences. Trends Neurosci 2004;27:48-53.

83. Kruk JS, Kouchmeshky A, Grimberg N, Rezkella M, Beazely MA. Transactivation of receptor tyrosine kinases by dopamine receptors. Dopamine Receptor Technologies. New York, NY: Springer New York; 2015. pp. 211-27.

84. Gill RS, Hsiung MS, Sum CS, Lavine N, Clark SD, et al. The dopamine D4 receptor activates intracellular platelet-derived growth factor receptor beta to stimulate ERK1/2. Cell Signal 2010;22:285-90.

85. Heeneman S, Haendeler J, Saito Y, Ishida M, Berk BC. Angiotensin II induces transactivation of two different populations of the plateletderived growth factor beta receptor. Key role for the p66 adaptor protein Shc. J Biol Chem 2000;275:15926-32.

86. Shen Y, Monsma FJ Jr, Metcalf MA, Jose PA, Hamblin MW, et al. Molecular cloning and expression of a 5-hydroxytryptamine7 serotonin receptor subtype. J Biol Chem 1993;268:18200-4.

87. Thomas DR, Hagan JJ. 5-HT7 receptors. Curr Drug Targets CNS Neurol Disord 2004;3:81-90.

88. Speranza L, Labus J, Volpicelli F, Guseva D, Lacivita E, et al. Serotonin 5-HT7 receptor increases the density of dendritic spines and facilitates synaptogenesis in forebrain neurons. J Neurochem 2017;141:647-61.

89. Vasefi MS, Kruk JS, Liu H, Heikkila JJ, Beazely MA. Activation of 5-HT7 receptors increases neuronal platelet-derived growth factor beta receptor expression. Neurosci Lett 2012;511:65-9.

90. Samarajeewa A, Goldemann L, Vasefi MS, Ahmed N, Gondora N, et al. 5-HT7 receptor activation promotes an increase in TrkB receptor expression and phosphorylation. Front Behav Neurosci 2014;8:391.

91. Kotecha SA, Oak JN, Jackson MF, Perez Y, Orser BA, et al. A D2 class dopamine receptor transactivates a receptor tyrosine kinase to inhibit NMDA receptor transmission. Neuron 2002;35:1111-22.

92. Vasefi MS, Yang K, Li J, Kruk JS, Heikkila JJ, et al. Acute 5-HT7 receptor activation increases NMDA-evoked currents and differentially alters NMDA receptor subunit phosphorylation and trafficking in hippocampal neurons. Mol Brain 2013;6:24.

93. Kanki H, Sasaki T, Matsumura S, Yokawa S, Yukami T, et al. beta-arrestin-2 in PAR-1-biased signaling has a crucial role in endothelial function via PDGF-beta in stroke. Cell Death Dis 2019;10:100.

94. Abassi M, Morawski BM, Nakigozi G, Nakasujja N, Kong X, et al. Cerebrospinal fluid biomarkers and HIV-associated neurocognitive disorders in HIV-infected individuals in Rakai, Uganda. J Neurovirol 2017;23:369-75.

95. Jung KH, Chu K, Lee ST, Bahn JJ, Jeon D, et al. Multipotent PDGFRbeta-expressing cells in the circulation of stroke patients. Neurobiol Dis 2011;41:489-97.

96. Bjorkqvist M, Ohlsson M, Minthon L, Hansson O. Evaluation of a previously suggested plasma biomarker panel to identify Alzheimer's disease. PLoS One 2012;7:e29868.

97. Rocha de Paula M, Gomez Ravetti M, Berretta R, Moscato P. Differences in abundances of cell-signalling proteins in blood reveal novel biomarkers for early detection of clinical Alzheimer's disease. PLoS One 2011;6:e17481.

98. Hu WT, Chen-Plotkin A, Arnold SE, Grossman M, Clark CM, et al. Novel CSF biomarkers for Alzheimer's disease and mild cognitive impairment. Acta Neuropathol 2010;119:669-78.

99. Mahlknecht P, Stemberger S, Sprenger F, Rainer J, Hametner E, et al. An antibody microarray analysis of serum cytokines in 
neurodegenerative Parkinsonian syndromes. Proteome Sci 2012;10:71.

100. Furukawa T, Matsui N, Fujita K, Nodera H, Shimizu F, et al. CSF cytokine profile distinguishes multifocal motor neuropathy from progressive muscular atrophy. Neurol Neuroimmunol Neuroinflamm 2015;2:e138.

101. Frydecka D, Krzystek-Korpacka M, Lubeiro A, Stramecki F, Stanczykiewicz B, et al. Profiling inflammatory signatures of schizophrenia: A cross-sectional and meta-analysis study. Brain Behav Immun 2018;71:28-36.

102. Zai G, Zai C, Tiwari A, King N, Braithwaite J, van Tol H, et al. Weak association of the platelet-derived growth factor beta (PDGFB) and PDGF receptor beta (PDGFRB) genes with schizophrenia and schizoaffective disorder. World J Biol Psychiatry 2011;12:127-33.

103. Vanlandewijck M, Lebouvier T, Andaloussi Mae M, Nahar K, Hornemann S, et al. Functional characterization of germline mutations in PDGFB and PDGFRB in primary familial brain calcification. PLoS One 2015;10:e0143407.

104. Nicolas G, Charbonnier C, de Lemos RR, Richard AC, Guillin O, et al. Brain calcification process and phenotypes according to age and sex: lessons from SLC20A2, PDGFB, and PDGFRB mutation carriers. Am J Med Genet B Neuropsychiatr Genet 2015;168:586-94. 